\title{
Ten-year trends in stroke admissions and outcomes in Canada
}

\author{
Noreen Kamal, M. Patrice Lindsay, Robert Côté, Jiming Fang, Moira K. Kapral, \\ Michael D. Hill
}

\begin{abstract}
Background: We analyzed a 10-year stroke administrative dataset to examine trends in admissions, mortality, and discharge destination in Canada. Methods: We conducted an analysis of hospital administrative data from April $1^{\text {st }} 2003$ to March $31^{\text {st }}$ 2013 from the Canadian Institute of Health Information's Discharge Abstract Database. Ten-year trends for population-based age- and sexstandardized admission rates were calculated. We reviewed 10-year trends in absolute stroke admissions for differences between provinces and age groups. Stroke 30-day in-hospital mortality rates were calculated and adjusted for sex, age, stroke type and comorbidities. We documented changes in discharge location for ischemic and hemorrhagic stroke patients discharged from acute care. Results: The rate of hospital admissions has declined from 140.2 to 117.5 (per 100,000 people). The number of absolute stroke admissions within provinces increased in Alberta and British Columbia (21.7\% and 16.2\% respectively). The proportion of stroke patients aged 40-69 years old increased by $4.8 \%(\mathrm{p}<0.0001)$ over the 10 years, whereas the proportion aged over 70 decreased by $4.9 \%$ ( $\mathrm{p}<0.0001)$. Risk-adjusted 30-day in-hospital mortality decreased from: $18.5 \%$ to $14.9 \%$ for all strokes; $15.2 \%$ to $12.1 \%$ for ischemic strokes; $35.6 \%$ to $29.7 \%$ for intracerebral hemorrhage; and $25.1 \%$ to $18.0 \%$ for subarachnoid hemorrhage. The absolute increase in patients requiring inpatient and outpatient support increased by $4 \%(\mathrm{p}<0.0001)$. Conclusion: The rate of admissions for stroke is decreasing but there is an increase in stroke admissions for younger patients. In-hospital mortality is decreasing; fewer patients are going directly home without services and more are requiring support services.
\end{abstract}

RÉSUMÉ: Tendances décennales des hospitalisations et des résultats concernant les accidents vasculaires cérébraux au Canada. Contexte: Nous avons analysé les données administratives décennales des hospitalisations, de la mortalité et de la destination au moment du congé hospitalier des patients atteints d'accidents vasculaires cérébraux (AVC) au Canada. Méthode: Nous avons analysé les données administratives hospitalières du 1 er avril 2003 au 31 mars 2013 contenues dans la base de données de l'Institut canadien d'information sur la santé. Nous avons calculé les tendances décennales pour les taux d'admission selon la population, standardisés pour l'âge et le sexe. Nous avons revu les tendances des taux d'hospitalisation pour AVC pour détecter des différences entre les provinces et les groupes d'âges. Les taux de mortalité hospitalière due à l'AVC dans les 30 premiers jours ont été calculés et ajustés pour le sexe, l'âge, le type d'AVC et les comorbidités. Nous avons documenté les changements dans la destination au congé hospitalier pour les patients atteints d'un AVC ischémique et d'un AVC hémorragique. Résultats: Le taux d'hospitalisation a diminué, passant de 140,2 à 117,5 (par 100,000 habitants). Le nombre absolu d'hospitalisations pour AVC dans chaque province a augmenté en Alberta et en Colombie Britannique (21,7\% et 16,2\% respectivement). La proportion de patients de 40 à 69 ans atteints d'un AVC a augmenté de 4,8\% (p<0,0001) au cours de ces 10 ans alors que la proportion de ceux de plus de 70 ans a diminué de 4,9\% (p <0,0001). La mortalité hospitalière dans les 30 jours de l'admission, ajustée pour le risque, a diminuée de $18,5 \%$ à $14,9 \%$ pour tous les AVC; de $15,2 \%$ à $12,1 \%$ pour les AVC ischémiques; de $35,6 \%$ à 29,7\% pour les hémorragies intracérébrales et de $25,1 \%$ à $18,0 \%$ pour les hémorragies sous-arachnoïdiennes. L'augmentation absolue du nombre de patients nécessitant un soutien hospitalier et extrahospitalier a augmenté de $4 \%$ ( $p<0,0001)$. Conclusion: Le taux d'hospitalisation pour AVC est en décroissance, mais il y a une augmentation des admissions pour un AVC de patients plus jeunes. La mortalité hospitalière diminue; moins de patients retournent directement à leur domicile sans services d'appoint et un plus grand nombre de patients a besoin de tels services.

Keywords: Epidemiology, stroke, trends, patient admission, quality of care, mortality

doi:10.1017/cjn.2015.20

Can J Neurol Sci. 2015; 42: 168-175

Stroke mortality is decreasing in Western European countries, ${ }^{1-4}$ the United States of America (USA) ${ }^{4}$ and globally. ${ }^{1}$ The incidence of stroke is also declining or stable in the USA, ${ }^{6}$ China, ${ }^{8}$
Japan, ${ }^{9,10}$ Denmark, ${ }^{11}$ Finland, ${ }^{3}$ France, ${ }^{4}$ England $^{12}$ and New Zealand. ${ }^{13}$ Conversely, stroke mortality is increasing in Eastern European and Central Asian countries. ${ }^{14}$ Stroke demographics are

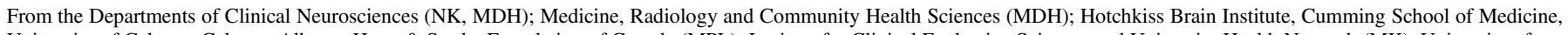
University of Calgary, Calgary, Alberta; Heart \& Stroke Foundation of Canada (MPL); Institute for Clinical Evaluative Sciences and University Health Network (MK), University of

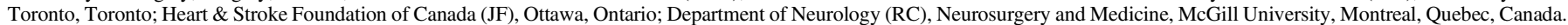
Received SePtember 3, 2014. Final Revisions Submitted December 23, 2014.

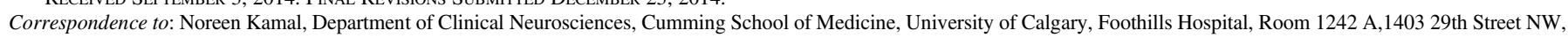
Calgary, Alberta, T2N 2T9, Canada. Email: nrkamal@ucalgary.ca 


\section{Table 1: ICD-10 Codes Used}

\begin{tabular}{|c|c|c|}
\hline Acute Stroke Main Category $^{+}$ & ICD-10 codes & Definition \\
\hline \multirow[t]{3}{*}{ Acute Ischemic stroke } & $163 \cdot x^{a}$ & Cerebral infarction \\
\hline & $164 . \mathrm{x}$ & Stroke, not specified as hemorrhage or infarction \\
\hline & H34.1 & Central retina artery occlusion \\
\hline Subarachnoid hemorrhage & $160 . \mathrm{x}^{\mathrm{b}}$ & Subarachnoid hemorrhage \\
\hline Intracerebral hemorrhage & 161.x & Intracerebral hemorrhage \\
\hline
\end{tabular}

${ }^{+}$Includes all patients where there is a Prefix Q for query or suspected diagnosis

${ }^{\mathrm{a}}$ Excludes I63.6, cerebral infarction due to cerebral venous thrombosis, nonpyogenic

${ }^{\mathrm{b}}$ Excludes I60.8, other subarachnoid hemorrhage (Meningeal hemorrhage and rupture of cerebral arteriovenous malformation)

changing with the aging of western populations. ${ }^{15,16}$ Yet, stroke continues to be a significant burden, as the second leading cause of death worldwide. ${ }^{17}$ Not all stroke mortality data from these studies are equivalent, as some used all-cause mortality per $100,000,{ }^{1,5,6}$ others 28-day mortality after first stroke, ${ }^{3,4}$ and others used 30-day, 1-year and 5-year mortality for first stroke hospitalization. ${ }^{2}$ Where trends in mortality were reviewed by stroke types, reductions in both ischemic and hemorrhagic stroke mortality were observed.
Reduced rates of stroke in-hospital mortality may have an effect on discharge destination, and consequently the need for support services. For example, more patients may require inpatient rehabilitation or long-term care as more stroke patients are surviving. Factors such as hospital type, patient demographics, and stroke type have been shown to affect discharge destination. ${ }^{18,19}$ Trends in discharge destination reflect improvement in acute stroke care but suggest that rehabilitative services and long-term care will require ongoing improvement to respond to an increase in demand.

Table 2: Absolute hospital admissions for stroke for Canada by Province

\begin{tabular}{|c|c|c|c|c|c|c|c|c|c|c|}
\hline Province & 2003 & 2004 & 2005 & 2006 & 2007 & 2008 & 2009 & 2010 & 2011 & 2012 \\
\hline \multicolumn{11}{|l|}{ All Strokes } \\
\hline Newfoundland & 718 & 641 & 715 & 708 & 715 & 701 & 643 & 691 & 652 & 658 \\
\hline Prince Edward Island & 227 & 192 & 183 & 160 & 183 & 177 & 189 & 187 & 179 & 218 \\
\hline Nova Scotia & 1157 & 1211 & 1284 & 1042 & 1141 & 1198 & 1167 & 1286 & 1262 & 1253 \\
\hline New Brunswick & 1153 & 1062 & 1131 & 1036 & 1028 & 998 & 959 & 1014 & 1003 & 1091 \\
\hline Quebec & - & - & - & - & - & 9007 & 8837 & 9194 & 9070 & - \\
\hline Ontario & 14514 & 14408 & 14591 & 14221 & 14208 & 14241 & 14456 & 14779 & 14522 & 14873 \\
\hline Manitoba & - & 1503 & 1528 & 1408 & 1508 & 1463 & 1399 & 1474 & 1439 & 1523 \\
\hline Saskatchewan & 1439 & 1428 & 1384 & 1483 & 1334 & 1376 & 1339 & 1330 & 1372 & 1358 \\
\hline Alberta & 2966 & 2984 & 3071 & 3068 & 3037 & 3154 & 3158 & 3262 & 3565 & 3609 \\
\hline British Columbia & 4857 & 5042 & 5014 & 4964 & 4828 & 5090 & 5049 & 5480 & 5570 & 5646 \\
\hline All Territories & 43 & 50 & 65 & 48 & 60 & 68 & 78 & 68 & 48 & 66 \\
\hline \multicolumn{11}{|l|}{ Ischemic Stroke } \\
\hline Newfoundland & 579 & 532 & 596 & 600 & 600 & 575 & 552 & 585 & 512 & 507 \\
\hline Prince Edward Island & 203 & 176 & 155 & 137 & 166 & 158 & 160 & 171 & 167 & 195 \\
\hline Nova Scotia & 980 & 1037 & 1087 & 862 & 965 & 995 & 975 & 1063 & 1055 & 1054 \\
\hline New Brunswick & 998 & 913 & 938 & 849 & 832 & 822 & 786 & 831 & 789 & 887 \\
\hline Quebec & - & - & - & - & - & 7020 & 6812 & 7196 & 7052 & - \\
\hline Ontario & 11806 & 11732 & 11809 & 11463 & 11421 & 11458 & 11530 & 11869 & 11658 & 11940 \\
\hline Manitoba & - & 1231 & 1273 & 1131 & 1221 & 1204 & 1130 & 1195 & 1161 & 1248 \\
\hline Saskatchewan & 1257 & 1215 & 1170 & 1236 & 1150 & 1152 & 1128 & 1107 & 1145 & 1155 \\
\hline Alberta & 2428 & 2417 & 2503 & 2482 & 2524 & 2518 & 2588 & 2695 & 2911 & 2966 \\
\hline British Columbia & 3881 & 4016 & 3935 & 3938 & 3758 & 4024 & 4016 & 4345 & 4419 & 4479 \\
\hline All Territories & 39 & 42 & 52 & 37 & 48 & 57 & 69 & 56 & 44 & 56 \\
\hline
\end{tabular}


Table 2. Continued

\begin{tabular}{l|c|c|c|c|c|c|r|r|r|r|r}
\hline Province & $\mathbf{2 0 0 3}$ & $\mathbf{2 0 0 4}$ & $\mathbf{2 0 0 5}$ & $\mathbf{2 0 0 6}$ & $\mathbf{2 0 0 7}$ & $\mathbf{2 0 0 8}$ & $\mathbf{2 0 0 9}$ & $\mathbf{2 0 1 0}$ & $\mathbf{2 0 1 1}$ & $\mathbf{2 0 1 2}$ \\
\hline Intracerebral Hemorrhagic Stroke (ICH) \\
\hline Newfoundland & 98 & 77 & 83 & 75 & 78 & 87 & 66 & 72 & 92 & 114 \\
\hline Prince Edward Island & 21 & 15 & 26 & 19 & 15 & 16 & 27 & 14 & 9 & 22 \\
\hline Nova Scotia & 95 & 103 & 136 & 117 & 122 & 139 & 135 & 150 & 131 & 146 \\
\hline New Brunswick & 98 & 107 & 140 & 131 & 140 & 122 & 129 & 139 & 155 & 147 \\
\hline Quebec & - & - & - & - & - & 1345 & 1413 & 1390 & 1405 & - \\
\hline Ontario & 1982 & 1891 & 1902 & 1887 & 1940 & 1883 & 2047 & 1978 & 1971 & 2060 \\
\hline Manitoba & - & 180 & 172 & 179 & 204 & 166 & 169 & 181 & 183 & 182 \\
\hline Saskatchewan & 126 & 141 & 163 & 172 & 129 & 153 & 144 & 159 & 158 & 141 \\
\hline Alberta & 347 & 347 & 369 & 383 & 310 & 429 & 385 & 354 & 460 & 428 \\
\hline British Columbia & 654 & 699 & 719 & 694 & 702 & 716 & 699 & 732 & 792 & 822 \\
\hline All Territories & 1 & 2 & 7 & 6 & 8 & 5 & 3 & 8 & 1 & 4 \\
\hline
\end{tabular}

Subarachnoid Hemorrhagic Stroke (SAH)

\begin{tabular}{l|r|r|r|r|r|r|r|r|r|r}
\hline Newfoundland & 41 & 32 & 36 & 33 & 37 & 39 & 25 & 34 & 48 & 37 \\
\hline Prince Edward Island & 3 & 1 & 2 & 4 & 2 & 3 & 2 & 2 & 3 & 1 \\
\hline Nova Scotia & 82 & 71 & 61 & 63 & 54 & 64 & 57 & 73 & 76 & 53 \\
\hline New Brunswick & 57 & 42 & 53 & 56 & 56 & 54 & 44 & 44 & 59 & 57 \\
\hline Quebec & - & - & - & - & - & 642 & 612 & 608 & 613 & - \\
\hline Ontario & 726 & 785 & 880 & 871 & 847 & 900 & 879 & 932 & 893 & 873 \\
\hline Manitoba & - & 92 & 83 & 98 & 83 & 93 & 100 & 98 & 95 & 93 \\
\hline Saskatchewan & 56 & 72 & 51 & 75 & 55 & 71 & 67 & 64 & 69 & 62 \\
\hline Alberta & 191 & 220 & 199 & 203 & 203 & 207 & 185 & 213 & 194 & 215 \\
\hline British Columbia & 322 & 327 & 360 & 332 & 368 & 350 & 334 & 403 & 359 & 345 \\
\hline All Territories & 3 & 6 & 6 & 5 & 4 & 6 & 6 & 4 & 3 & 6 \\
\hline
\end{tabular}

We reviewed 10-year trends in stroke occurrence and mortality for Canada. Specifically, we looked at stroke admissions across Canada by province and age group and stroke admission rates for

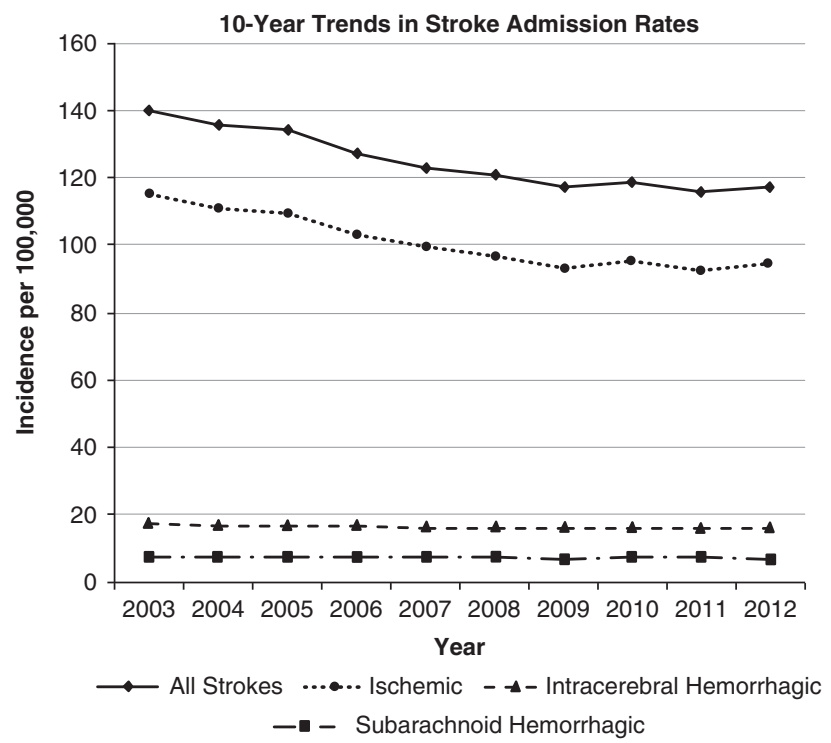

Figure 1: 10-year trends stroke admission risk adjusted rates (incidence per 100,000 population) for all stroke, ischemic stroke, intracerebral hemorrhagic stroke, and subarachnoid hemorrhagic stroke all stroke types. We also separately reviewed 30-day in-hospital mortality for all strokes, ischemic strokes, intracerebral hemorrhagic strokes, and subarachnoid hemorrhagic strokes. We reviewed discharge destination for all strokes, ischemic strokes and hemorrhagic strokes discharged alive from acute care.

\section{Methods}

We conducted an analysis of all stroke patients admitted to a hospital for acute care in Canada. Data are from the Canadian Institutes for Health Information (CIHI). The population of Canada in 2013 was $35,158,304$ compared to $31,641,630$ in $2003 .^{20}$ Canada has a universal healthcare system, where all Canadian citizens and permanent residents have access to hospital and physician care. Health services are administered by each of its ten provinces and three territories. The CIHI's Discharge Abstract Database (DAD) contains demographic, administrative and clinical data (including deaths, sign-outs and transfers) on all inpatient hospital discharges. All hospitals in Canada (with the exception of Quebec) are required to report to the DAD; Quebec reports their data through a different process. ${ }^{21}$ Analysis of hospital chart coding in teaching and community hospitals in Canada showed excellent positive predictive value ( $85 \%$ for ischemic stroke, $98 \%$ for intracerebral hemorrhagic stroke, and $91 \%$ for subarachnoid hemorrhagic stroke) with a Kappa statistic (as a measure of agreement between coder and researcher) of 0.89 for International 
Table 3: Number (Percent) of Stroke Admissions per Age Group

\begin{tabular}{|c|c|c|c|c|c|c|c|c|c|c|c|}
\hline AGE & 2003 & 2004 & 2005 & 2006 & 2007 & 2008 & 2009 & 2010 & 2011 & 2012 & \\
\hline 00 to 01 & $20(0.1 \%)$ & $32(0.1 \%)$ & $34(0.1 \%)$ & $34(0.1 \%)$ & $32(0.1 \%)$ & $28(0.1 \%)$ & $38(0.1 \%)$ & $28(0.1 \%)$ & $15(0 \%)$ & $8(0 \%)$ & \\
\hline 01 to 19 & $80(0.3 \%)$ & $82(0.3 \%)$ & $94(0.3 \%)$ & $80(0.3 \%)$ & $88(0.3 \%)$ & $118(0.3 \%)$ & $107(0.3 \%)$ & $105(0.3 \%)$ & $92(0.2 \%)$ & $63(0.2 \%)$ & \\
\hline 20 to 29 & $108(0.4 \%)$ & $137(0.5 \%)$ & $138(0.5 \%)$ & $144(0.5 \%)$ & $181(0.6 \%)$ & $229(0.6 \%)$ & $191(0.5 \%)$ & $185(0.5 \%)$ & $200(0.5 \%)$ & $176(0.6 \%)$ & \\
\hline 30 to 39 & $372(1.4 \%)$ & $406(1.4 \%)$ & $481(1.7 \%)$ & $392(1.4 \%)$ & $375(1.3 \%)$ & $558(1.5 \%)$ & $517(1.4 \%)$ & $527(1.4 \%)$ & $541(1.4 \%)$ & $430(1.4 \%)$ & \\
\hline 40 to 49 & $1172(4.3 \%)$ & $1374(4.8 \%)$ & $1476(5.1 \%)$ & $1441(5.1 \%)$ & $1470(5.2 \%)$ & $1866(5 \%)$ & $1918(5.1 \%)$ & $1988(5.1 \%)$ & $1912(4.9 \%)$ & $1387(4.6 \%)$ & \\
\hline 50 to 59 & $2557(9.4 \%)$ & $2766(9.7 \%)$ & $2994(10.3 \%)$ & $2850(10.1 \%)$ & $2974(10.6 \%)$ & $4086(10.9 \%)$ & $4174(11.2 \%)$ & $4445(11.5 \%)$ & $4459(11.5 \%)$ & $3595(11.9 \%)$ & \\
\hline 60 to 69 & $4380(16.2 \%)$ & $4467(15.7 \%)$ & $4516(15.6 \%)$ & $4626(16.4 \%)$ & $4768(17 \%)$ & $6620(17.7 \%)$ & $6545(17.6 \%)$ & $6992(18 \%)$ & $7133(18.4 \%)$ & $5563(18.4 \%)$ & \\
\hline 70 to 79 & $8134(30 \%)$ & $8447(29.6 \%)$ & $8191(28.3 \%)$ & $7661(27.2 \%)$ & $7598(27.1 \%)$ & $10066(26.9 \%)$ & $9700(26 \%)$ & $9948(25.7 \%)$ & $9771(25.3 \%)$ & $7499(24.8 \%)$ & \\
\hline 80 to 89 & $8222(30.4 \%)$ & $8704(30.5 \%)$ & $8833(30.5 \%)$ & $8714(31 \%)$ & $8383(29.9 \%)$ & $11003(29.4 \%)$ & $11135(29.9 \%)$ & $11304(29.2 \%)$ & $11243(29.1 \%)$ & $8852(29.2 \%)$ & \\
\hline $90+$ & $2029(7.5 \%)$ & $2106(7.4 \%)$ & $2209(7.6 \%)$ & $2196(7.8 \%)$ & $2173(7.7 \%)$ & $2899(7.7 \%)$ & $2949(7.9 \%)$ & $3243(8.4 \%)$ & $3316(8.6 \%)$ & $2722(9 \%)$ & \\
\hline Total & 27074 & 28521 & 28966 & 28138 & 28042 & 37473 & 37274 & 38765 & 38682 & 30295 & \\
\hline \multicolumn{11}{|l|}{ All Stroke } & $\mathbf{p}$ \\
\hline 00 to 39 & $580(2.1 \%)$ & $657(2.3 \%)$ & $747(2.6 \%)$ & $650(2.3 \%)$ & $676(2.4 \%)$ & $933(2.5 \%)$ & $853(2.3 \%)$ & $845(2.2 \%)$ & $848(2.2 \%)$ & $677(2.2 \%)$ & 0.128 \\
\hline 40 to 69 & $8109(30 \%)$ & $8607(30.2 \%)$ & $8986(31 \%)$ & $8917(31.7 \%)$ & $9212(32.9 \%)$ & $12572(33.5 \%)$ & $12637(33.9 \%)$ & $13425(34.6 \%)$ & $13504(34.9 \%)$ & $10545(34.8 \%)$ & $<0.0001$ \\
\hline Over 70 & $18385(67.9 \%)$ & $19257(67.5 \%)$ & $19233(66.4 \%)$ & $18571(66 \%)$ & $18154(64.7 \%)$ & $23968(64 \%)$ & $23784(63.8 \%)$ & $24495(63.2 \%)$ & $24330(62.9 \%)$ & $19073(63 \%)$ & $<0.0001$ \\
\hline \multicolumn{11}{|c|}{ Ischemic Stroke } & $\mathbf{p}$ \\
\hline 00 to 39 & $321(1.4 \%)$ & $384(1.6 \%)$ & $408(1.7 \%)$ & $395(1.7 \%)$ & $382(1.7 \%)$ & $529(1.8 \%)$ & $503(1.7 \%)$ & $486(1.6 \%)$ & $498(1.6 \%)$ & $419(1.7 \%)$ & 0.563 \\
\hline 40 to 69 & $5967(26.9 \%)$ & $6272(26.9 \%)$ & $6582(28 \%)$ & $6524(28.7 \%)$ & $6814(30 \%)$ & $9235(30.8 \%)$ & $9229(31 \%)$ & $9963(32 \%)$ & $10048(32.5 \%)$ & $7906(32.3 \%)$ & $<0.0001$ \\
\hline Over 70 & $15883(71.6 \%)$ & $16655(71.4 \%)$ & $16528(70.3 \%)$ & $15816(69.6 \%)$ & $15489(68.3 \%)$ & $20219(67.4 \%)$ & $20014(67.3 \%)$ & $20664(66.4 \%)$ & $20367(65.9 \%)$ & $16162(66 \%)$ & $<0.0001$ \\
\hline \multicolumn{11}{|c|}{ Intracerebral hemorrhagic Stroke } & $\mathbf{p}$ \\
\hline 00 to 39 & $122(3.6 \%)$ & $130(3.6 \%)$ & $170(4.6 \%)$ & $131(3.6 \%)$ & $136(3.7 \%)$ & $165(3.3 \%)$ & $176(3.4 \%)$ & $186(3.6 \%)$ & $157(2.9 \%)$ & $124(3 \%)$ & 0.002 \\
\hline 40 to 69 & $1158(33.8 \%)$ & $1211(34 \%)$ & $1264(34 \%)$ & $1212(33.1 \%)$ & $1253(34.3 \%)$ & $1739(34.4 \%)$ & $1831(35.1 \%)$ & $1792(34.6 \%)$ & $1862(34.8 \%)$ & $1497(36.8 \%)$ & 0.003 \\
\hline Over 70 & $2142(62.6 \%)$ & $2221(62.4 \%)$ & $2283(61.4 \%)$ & $2320(63.3 \%)$ & $2259(61.9 \%)$ & $3157(62.4 \%)$ & $3210(61.5 \%)$ & $3199(61.8 \%)$ & $3338(62.3 \%)$ & $2445(60.1 \%)$ & 0.084 \\
\hline \multicolumn{11}{|c|}{ Subarachnoid hemorrhagic Stroke } & $\mathbf{p}$ \\
\hline 00 to 39 & $137(9.3 \%)$ & $143(8.7 \%)$ & $169(9.8 \%)$ & $124(7.1 \%)$ & $158(9.2 \%)$ & $239(9.8 \%)$ & $174(7.5 \%)$ & $173(7 \%)$ & $193(8 \%)$ & $134(7.7 \%)$ & 0.006 \\
\hline 40 to 69 & $984(66.4 \%)$ & $1124(68.2 \%)$ & $1140(65.9 \%)$ & $1181(67.9 \%)$ & $1145(67 \%)$ & $1598(65.8 \%)$ & $1577(68.2 \%)$ & $1670(67.5 \%)$ & $1594(66.1 \%)$ & $1142(65.6 \%)$ & 0.481 \\
\hline Over 70 & $360(24.3 \%)$ & $381(23.1 \%)$ & $422(24.4 \%)$ & $435(25 \%)$ & $406(23.8 \%)$ & $592(24.4 \%)$ & $560(24.2 \%)$ & $632(25.5 \%)$ & $625(25.9 \%)$ & $466(26.8 \%)$ & 0.012 \\
\hline
\end{tabular}




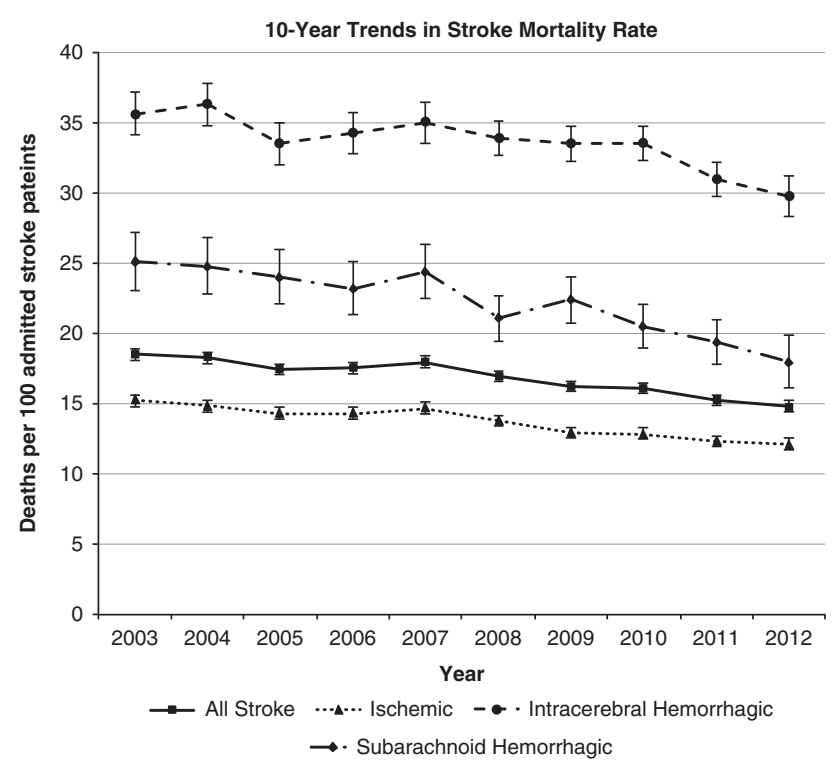

Figure 2: 10-year trends for 30-day in-hospital risk adjusted mortality rate (death per 100 admitted stroke patients) for all stroke, ischemic stroke, intracerebral hemorrhage, and subarachnoid hemorrhage. Error bars represent $95 \%$ Confidence Interval.

Statistical Classification of Diseases and Related Health Problems, 10th Revision (ICD-10) coding. ${ }^{22}$

We used hospital administrative data from April $1^{\text {st }} 2003$ to March $31^{\text {st }} 2013$ from the DAD. All acute care facilities in all Canadian provinces contributed to the DAD with the exception of Manitoba (began in April $1^{\text {st }}$ 2004) and Quebec (began in fiscal year 2008/09, ended in 2011/12). Therefore, all stroke patients admitted to hospital for acute care in Canada from April $1^{\text {st }} 2003$ to March $31^{\text {st }} 2013$ were included except for Manitoba and Quebec, who contributed only partially based on the above participation periods. Stroke patients were identified in our analysis using standardized case definitions based on ICD-10 codes for acute stroke, acute stroke plus transient ischemic attach (TIA), ischemic stroke, aneurysmal subarachnoid hemorrhage, and intracerebral hemorrhage. [Table 1]

Stroke admission rates were calculated and standardized using the direct method to the Canadian census. Ten-year trends were assessed using standardized rates. We used the Canadian census data (2001, 2006 and 2011) to estimate the population of 2003-2005, 2007-2010, and 2012; and adjusted 2011 data as the standard population. Stroke in-hospital mortality was defined as the risk-adjusted rate of all-cause in-hospital death occurring within 30 days of first admission to an acute care hospital with a diagnosis of stroke. Specifically, the numerator is the number of deaths from all causes occurring in hospital within 30 days of admission for stroke and the denominator is the total number of stroke episodes. ${ }^{23} \mathrm{We}$ included stroke that occurred during hospitalization as a complication of hospital admission for another reason. Risk-adjusted rates were adjusted for age, sex, stroke type (ischemic vs. hemorrhagic) and comorbid illness defined by the Charlson-Deyo index (0-1 vs. $2+$ ). Discharge location categories are: home without services; home with services; inpatient rehabilitation or other acute care facility; complex continuing care; long term care; and other. All statistical comparisons were done using Cochran-Armitage Trend Test via SAS 9.3 (SAS Institute Inc., Cary, NC, USA).

\section{RESULTS \\ Stroke Admissions}

We identified 323230 stroke hospital admissions in Canada from April 2003 to March 2013. Table 2 shows the absolute stroke (all), ischemic stroke, intracerebral hemorrhage, and subarachnoid hemorrhage admissions in Canada over 10 years for each province. We note that absolute numbers of stroke admissions were stable or declining in most provinces except Alberta $(\mathrm{AB})$ and British Columbia (BC), where an increase in stroke numbers was observed. In relative terms, there was an increase in stroke admissions in those provinces of $21.7 \%(\mathrm{AB})$ and $16.2 \%(\mathrm{BC})$. Similar trends were observed for ischemic stroke admissions with an increase of $23.3 \%$ in $\mathrm{AB}$ and $15.4 \%$ in $\mathrm{BC}$. For intracerebral hemorrhage, increases over the 10-year period were present for all provinces with increases ranging from 50\% (New Brunswick) to $4 \%$ (Ontario). For subarachnoid hemorrhage, increases were present in Ontario (20.2\%), Saskatchewan (10.7\%), AB (12.6\%), and BC (7.1\%).

Figure 1 shows the standardized risk-adjusted rates of stroke admissions over the 10-year period. The standardized rate of ischemic stroke admissions has dropped by $17.7 \%$. However, the rate of intracerebral hemorrhage and subarachnoid hemorrhage has dropped much less dramatically (10.0\% and $7.9 \%$ respectively).

A higher proportion of admitted stroke patients were in younger age groups in 2012 compared to 2003 (Table 3). Stroke (all) and ischemic stroke in patients aged less than 40 years old has been stable. For patients aged between 40 and 69, the absolute increase for all strokes was $4.8 \%(\mathrm{p}<0.0001)$ and for ischemic strokes, $5.4 \%(\mathrm{p}<0.0001)$. For patients 70 years old and older, the absolute decrease for all strokes was $4.9 \%(\mathrm{p}<0.0001)$ and for ischemic strokes, $5.6 \%(\mathrm{p}<0.0001)$. The changes for intracerebral hemorrhage and subarachnoid hemorrhage were less dramatic.

\section{In-hospital Mortality}

We observed a decline for in-hospital 30-day mortality for all stroke patients (Figure 2). For all stroke patients, mortality fell between 2003 to 2012 from $18.5 \%$ (95\% CI: 18.1\%-18.9\%) to $14.9 \%$ (95\% CI: $14.4 \%-15.2 \%$ ). For ischemic stroke, it went down from $15.2 \%$ (95\% CI: $14.8 \%-15.7 \%$ ) to $12.1 \%$ (95\% CI: $11.7 \%-12.5 \%)$. For intracerebral hemorrhage, mortality fell from $35.6 \%$ (95\% CI: $34.1 \%-37.1 \%$ ) to $29.7 \%$ (95\% CI: $28.3 \%-31.1 \%$ ). For subarachnoid hemorrhage, mortality dropped from $25.1 \%(95 \%$ CI: $23.0 \%-27.2 \%$ ) to $18.0 \%$ (95\% CI: $16.1 \%-19.8 \%$ ).

\section{Discharge Destination}

The discharge destination for all stroke patients discharged alive from acute care is shown in Table 4. For ischemic stroke patients, the following changes were observed: an absolute decrease in the percent of patients discharged home without services by $3.2 \%(p=0.0463)$; an absolute increase in the percent discharged home with services by $2.6 \%$ ( $p<0.0001)$; an absolute increase in the percent of patients discharged to another inpatient acute care facility including inpatient rehabilitation by $5.6 \%$ (both $\mathrm{p}<0.0001$ ), an absolute decrease in the percent being discharged to complex continuing care by $0.9 \%(\mathrm{p}<0.0001)$ and long term care by $1.9 \%(\mathrm{p}<0.0001)$. For hemorrhagic strokes, the following 


\begin{tabular}{|c|c|c|c|c|c|c|c|c|c|c|c|}
\hline Year & 2003 & 2004 & 2005 & 2006 & 2007 & 2008 & 2009 & 2010 & 2011 & 2012 & $\mathbf{p}$ \\
\hline \multicolumn{12}{|l|}{ ALL STROKE } \\
\hline Home without Services & $9002(41.8 \%)$ & $9390(41.1 \%)$ & $9267(39.5 \%)$ & $8643(38.2 \%)$ & $8905(39.6 \%)$ & $12758(42.1 \%)$ & $12844(42.2 \%)$ & $13357(42 \%)$ & $13581(42.3 \%)$ & $9810(38.7 \%)$ & $<0.0001$ \\
\hline $\begin{array}{l}\text { Inpatient Rehabilitation \& } \\
\text { other acute facility }\end{array}$ & $5990(28.8 \%)$ & $6815(29.9 \%)$ & $7004(29.8 \%)$ & $6960(30.8 \%)$ & $6961(30.9 \%)$ & $8982(29.6 \%)$ & $9028(29.7 \%)$ & $9832(30.9 \%)$ & $10046(31.5 \%)$ & $8578(33.9 \%)$ & $<0.0001$ \\
\hline Complex Contin. Care & $1444(6.7 \%)$ & $1496(6.5 \%)$ & $1659(7.1 \%)$ & $1636(7.2 \%)$ & $1540(6.9 \%)$ & $1604(5.3 \%)$ & $1673(5.5 \%)$ & $1630(5.1 \%)$ & $1537(4.8 \%)$ & $1543(6.1 \%)$ & $<0.0001$ \\
\hline \multicolumn{12}{|l|}{ ISCHEMIC STROKE } \\
\hline Home without Services & $7795(42.6 \%)$ & $8151(42 \%)$ & $7916(40.1 \%)$ & $7345(38.8 \%)$ & $7524(39.9 \%)$ & $10766(42.7 \%)$ & $10881(43.1 \%)$ & $11306(42.7 \%)$ & $11435(43 \%)$ & $8322(39.4 \%)$ & 0.0463 \\
\hline Home with Services & $1909(10.4 \%)$ & $2079(10.7 \%)$ & $2416(12.2 \%)$ & $2393(12.6 \%)$ & $2370(12.6 \%)$ & $3159(12.5 \%)$ & $3231(12.8 \%)$ & $3290(12.4 \%)$ & $3274(12.3 \%)$ & $2741(13 \%)$ & $<0.0001$ \\
\hline $\begin{array}{c}\text { Inpatient Rehabilitation \& } \\
\text { other acute facility }\end{array}$ & $4890(26.7 \%)$ & $5449(28.1 \%)$ & $5521(28 \%)$ & $5450(28.8 \%)$ & $5547(29.4 \%)$ & $7001(27.8 \%)$ & $6962(27.6 \%)$ & $7719(29.2 \%)$ & $7837(29.5 \%)$ & $6825(32.3 \%)$ & $<0.0001$ \\
\hline Complex Contin. Care & $1288(7 \%)$ & $1295(6.7 \%)$ & $1436(7.3 \%)$ & $1398(7.4 \%)$ & $1318(7 \%)$ & $1331(5.3 \%)$ & $1404(5.6 \%)$ & $1373(5.2 \%)$ & $1293(4.9 \%)$ & $1284(6.1 \%)$ & $<0.0001$ \\
\hline Home with Services & $220(6.8 \%)$ & $261(7.6 \%)$ & $291(7.8 \%)$ & $258(7 \%)$ & $271(7.5 \%)$ & $394(7.7 \%)$ & $414(8 \%)$ & $406(7.6 \%)$ & $436(7.8 \%)$ & $354(8.4 \%)$ & 0.0214 \\
\hline $\begin{array}{c}\text { Inpatient Rehabilitation \& } \\
\text { other acute facility }\end{array}$ & $1300(40.2 \%)$ & $1366(39.8 \%)$ & $1483(39.8 \%)$ & $1510(41.2 \%)$ & $1414(39.3 \%)$ & $1981(38.5 \%)$ & $2066(40.1 \%)$ & $2113(39.8 \%)$ & $2220(39.9 \%)$ & $1758(41.7 \%)$ & 0.4496 \\
\hline Complex Contin. Care & $156(4.8 \%)$ & $201(5.8 \%)$ & $223(6 \%)$ & $238(6.5 \%)$ & $222(6.2 \%)$ & $273(5.3 \%)$ & $269(5.2 \%)$ & $257(4.8 \%)$ & $244(4.4 \%)$ & $260(6.2 \%)$ & 0.056 \\
\hline Long Term Care & $196(6.1 \%)$ & $217(6.3 \%)$ & $206(5.5 \%)$ & $218(5.9 \%)$ & $200(5.6 \%)$ & $372(7.2 \%)$ & $335(6.5 \%)$ & $380(7.2 \%)$ & $400(7.2 \%)$ & $206(4.9 \%)$ & 0.1809 \\
\hline Other & $151(4.7 \%)$ & $152(4.4 \%)$ & $169(4.5 \%)$ & $147(4 \%)$ & $113(3.1 \%)$ & $127(2.5 \%)$ & $108(2.1 \%)$ & $101(1.9 \%)$ & $90(1.6 \%)$ & $122(2.9 \%)$ & $<0.0001$ \\
\hline
\end{tabular}

Contin. $=$ Continuing 
changes were observed: an absolute decrease in the percent discharged home without services by $1.7 \%(\mathrm{p}=0.0249)$, and an absolute increase in the percent discharged home with services of $1.6 \%(\mathrm{p}=0.0214)$.

\section{DISCUSSION}

Ten-year trends for hospitalized stroke patients in Canada show that absolute stroke admissions are not equal across provinces. When looking at absolute numbers, those provinces that have had large increases in population are shouldering a stark increase in ischemic stroke admissions; this has implications if funding for stroke services does not match the demands of population increases. When taking population increases into account, standardized risk adjusted admission rates have been decreasing for ischemic stroke but the decrease is much less dramatic for intracerebral and subarachnoid hemorrhage. This finding is somewhat similar to an earlier Quebec study (trends from 1990-2005) where ischemic stroke admissions in Quebec were declining but hemorrhagic stroke admissions were increasing $^{24}$ - in contrast we saw a very slight decline in hemorrhagic stroke admissions. This decrease in stroke admission rates may be due to better hypertension control, ${ }^{25}$ improved stroke prevention strategies, more proactive secondary prevention through the implementation of stroke prevention clinics across Canada or other unmeasured factors. The decline in stroke rates and case fatality and the relative increase in younger strokes can be explained in part by Ontario data on trends in risk factors and stroke subtypes, ${ }^{26}$ which showed a relative increase in cardioembolic stroke due to a decrease in large artery stroke and small vessel disease.

The distribution of age groups of stroke admissions is changing and is likely associated with the increasing age of the baby boomer cohort. The proportion of ischemic stroke patients aged 40-69 years old is increasing, and the proportion aged 70 and older is decreasing. A shift to a younger age group was also observed for intracerebral hemorrhagic stroke, where the proportion of patients in age groups under 40 and between 40 and 69 years old is increasing. An increase in the younger stroke victims, who are at the peak of their career and active role in society, will have greater indirect socioeconomic consequences in lost wages and increased costs of caring for younger disabled adults, despite a declining age-adjusted rate overall.

Similar to the findings from the USA and Western European countries, ${ }^{1-4}$ stroke mortality was lower in Canada in 2012 compared to 2003. This holds true for ischemic stroke, intracerebral hemorrhage, and subarachnoid hemorrhage. The decrease in mortality can be attributed to better specialized medical care, prevention of secondary complications, and the implementation of in-hospital stroke units. However, the decline in mortality may translate into an overall increase in the number of patients with substantial functional deficits. When we reviewed trends in discharge destinations for stroke patients discharged alive from acute care, we observed a decrease in the percentage of ischemic and hemorrhagic stroke patients going home without services. There is an increase in ischemic stroke patients going to inpatient rehabilitation or other acute facilities, and ischemic and hemorrhagic stroke patients going home with services. However, there is a slight decrease observed in ischemic stroke patients going to complex continuing care and long-term care. The increase in patients going home with services (outpatient) and to inpatient rehabilitation or another acute care institutions is proportionate to the drop in in-hospital mortality, possibly suggesting that a decline in in-hospital mortality is contributing to the increased need for post-acute stroke services. Therefore, although more patients are surviving their stroke, the need for rehabilitation services is increasing.

\section{Limitations}

Our data uses only hospital administrative data, so it excludes patients who were never admitted to hospital, (mostly patients with milder strokes), as the number of stroke patients that die before they reach the hospital is small. ${ }^{27}$ Hospital administrative data is subject to differences in reporting, and despite rigorous abstraction processes, variation in reporting may still be present. Data from Quebec and Manitoba do not include the entire 10-year study period, so we are not reporting the entire 10-year period occurrence across Canada. The use of hospital administrative data requires that we include strokes that were coded as Stroke, not specified as hemorrhage or infarction with acute ischemic strokes. We acknowledge that this does present some error; however, over $80 \%$ of all strokes are ischemic strokes and, typically, an ischemic stroke is most often referred to as stroke generally for the small fraction that were coded as not specified.

\section{Conclusions}

Ten-year stroke trends in Canada show that admission rates and in-hospital mortality are declining. However, those provinces that are experiencing the largest population growths are shouldering a greater proportion of stroke admissions. This is observed for the two western provinces: Alberta and British Columbia. Furthermore, the proportion of stroke admissions by age groups is showing a significant increase for those patients aged 40-69 and a significant decrease for those patients aged over 70 . The decrease in mortality may also be contributing to more patients requiring inpatient and outpatient services.

\section{ACKNOWLEDGements AND Funding}

The authors acknowledge HSF Stroke Quality Advisory Committee members 2013-2015. Funding for this study was received from Heart and Stroke Foundation and the Canadian Stroke Network. Moira Kapral is supported by a Career Investigator Award from the Heart and Stroke Foundation, Ontario Provincial Office.

\section{Disclosures}

RC has the following disclosures: Pfizer, Consultant, Honoraria; Bayer, Consultant, Honoraria; BMS, Speaker, Honoraria; Sanofi, Speaker, Honoraria. MH, JF, PL, MK, AND NK do not have anything to disclose.

\section{REFERENCES}

1. Kunst AE, Amiri M, Janssen F. The Decline in Stroke Mortality Exploration of Future Trends in 7 Western European Countries. Stroke. 2011;42:2126-30.

2. Schmidt M, Jacobsen JB, Johnsen SP, Bøtker HE, Sørensen HT. Eighteen-year trends in stroke mortality and the prognostic influence of comorbidity. Neurology. 2014;82:340-50. 
3. Sivenius $\mathrm{J}$, Tuomilehto J, Immonen-Räihä $\mathrm{P}$, et al. Continuous 15-Year Decrease in Incidence and Mortality of Stroke in Finland The FINSTROKE Study. Stroke. 2004;35:420-5.

4. Benatru I, Rouaud O, Durier J, et al. Stable stroke incidence rates but improved case-fatality in Dijon, France, from 1985 to 2004. Stroke. 2006;37:1674-9.

5. Carandang R, Seshadri S, Beiser A, et al. Trends in incidence, lifetime risk, severity, and 30-day mortality of stroke over the past 50 years. JAMA. 2006;296:2939-46.

6. Broderick JP. Stroke trends in Rochester, Minnesota, during 1945 to 1984. Annals of Epidemiol. 1993;3:476-9.

7. Broderick JP, Phillips SJ, Whisnant JP, O'Fallon WM, Bergstralh EJ. Incidence rates of stroke in the eighties: the end of the decline in stroke? Stroke. 1989;20:577-82.

8. Cheng XM, Ziegler DK, Lai YHC, et al. Stroke in China, 1986 through 1990. Stroke. 1995;26:1990-4.

9. Kubo M, Kiyohara Y, Ninomiya T, et al. Decreasing incidence of lacunar vs other types of cerebral infarction in a Japanese population. Neurology. 2006;66:1539-44.

10. Morikawa Y, Nakagawa H, Naruse Y, et al. Trends in Stroke Incidence and Acute Case Fatality in a Japanese Rural Area The Oyabe Study. Stroke. 2000;31:1583-7.

11. Thorvaldsen P, Davidsen M, Brønnum-Hansen H, Schroll M. Stable stroke occurrence despite incidence reduction in an aging population stroke trends in the Danish monitoring trends and determinants in cardiovascular disease (MONICA) population. Stroke. 1999;30:2529-34.

12. Rothwell PM, Coull AJ, Giles MF, et al. Change in stroke incidence, mortality, case-fatality, severity, and risk factors in Oxfordshire, UK from 1981 to 2004 (Oxford Vascular Study). Lancet. 2004;363:1925-33.

13. Anderson CS, Carter KN, Hackett ML, et al. Trends in stroke incidence in Auckland, New Zealand, during 1981 to 2003. Stroke. 2005;36:2087-93.

14. Redon J, Olsen MH, Cooper RS, et al. Stroke mortality and trends from 1990 to 2006 in 39 countries from Europe and Central Asia: implications for control of high blood pressure. Eur Heart J. 2011;32:1424-31.

15. Niessen LW, Barendregt JJ, Bonneux L, Koudstaal PJ. Stroke trends in an aging population. The Technology Assessment Methods Project Team. Stroke. 1993;24:931-9.
16. Börsch-Supan A, Chiappori PA. Aging population: Problems and policy options in the US and Germany. Econ Policy. 1991; 104-39.

17. Lozano R, Naghavi M, Foreman K, et al. Global and regional mortality from 235 causes of death for 20 age groups in 1990 and 2010: a systematic analysis for the Global Burden of Disease Study 2010. Lancet. 2013;380:2095-128.

18. Mayo NE, Hendlisz J, Goldberg MS, Korner-Bitensky N, Becker R, Coopersmith H. Destinations of stroke patients from the Montreal area acute-care hospitals. Stroke. 1989;20:351-6.

19. Fonarow GC, Reeves MJ, Smith EE, et al. Characteristics, Performance Measures, and In-Hospital Outcomes of the First One Million Stroke and Transient Ischemic Attack Admissions in Get With The Guidelines-Stroke. Circ Cardiovasc Qual Outcomes. 2010;3:291-302.

20. Statistics Canada. Table 051-0001 - Estimates of population, by age group and sex for July 1, Canada, provinces and territories, annual (persons unless otherwise noted), CANSIM (database). (accessed: 2014-04-10).

21. Canadian Institute for Health Information. DAD Metadata. http:// www.cihi.ca/CIHI-ext-portal/internet/en/document/types+of+care/ hospital+care/acute+care/dad_metadata (accessed: 2014-04-30).

22. Kokotailo RA, Hill MD. Coding of stroke and stroke risk factors using international classification of diseases, revisions 9 and 10 . Stroke. 2005;36:1776-81.

23. Canadian Institute for Health Information. Health Indicators 2011: Definitions, Data Sources and Rationale, June 2011 http://www. cihi.ca/CIHI-ext-portal/pdf/internet/DEFINITIONS_062011_EN.

24. Mayo NE, Nadeau L, Daskalapoulou SS, Côté R. The evolution of stroke in Quebec: a 15-year perspective. Neurology. 2007;68: 1122-1127.

25. Campbell NR, McKay DW. Accurate blood pressure measurement: Why does it matter? Can Med Assoc J. 1999;161:277-8.

26. Bogiatzi C, Hackam DG, McLeod AI, Spence JD. Secular trends in ischemic stroke subtypes and stroke risk factors. Stroke. 2014;45: 3208-13.

27. Morgenstern LB, Smith MA, Lisabeth LD, et al. Excess stroke in Mexican Americans compared with non-Hispanic whites. The Brain Attack Surveillance in Corpus Christi Project. Am J Epidemiol. 2004;160:376-83. 